\title{
Ovarian Fibrothecoma Presenting as a Huge Pelvic Mass - A Case Report
}

\author{
Anishma M.J. ${ }^{1}$, Jayanthi R. ${ }^{2}$, Sahitya Meda $^{3}$
}

1, 2,3 Department of Obstetrics and Gynaecology, Meenakshi Medical College and Research Institute, Tamil Nadu, India.

\section{PRESENTATION OF CASE}

A 45-year-old para-2, live-2, sterilized woman presented with lower abdominal pain and fever of 10 days duration. She had history of decreased appetite, increased frequency of urination for the last four months. Her menstrual cycles were regular, with average flow, and had congestive dysmenorrhea for the last four months. Her temperature was $99.4^{\circ} \mathrm{F}$ and other vitals were within normal limits. Abdominal examination showed a huge stony hard mass of 34 weeks size, margins well defined, nontender, with restricted mobility. Other systemic examination were within normal limits. Speculum examination-cervix was hypertrophied and congested. Vaginal examination-mass felt on all fornices and it was immobile, uterus could not be separately felt from the mass.

USG $^{1}$ (Ultra-Sono-Graphy) revealed a hypoechoic mass of size 26.8 × 11.5 × 27.9 $\mathrm{cm}$ arising from posterior wall of the uterus, right ovary was not delineated due to overlying mass and left ovary normal, ET (Endometrial Thickness) - $5 \mathrm{~mm}$ IVP (IntraVenous Pyelogram) - showing bilateral hydronephrosis, CA125, ${ }^{2}$ CEA, $\beta$ HCG, AFP were within normal limits.

\section{DISCUSSION OF MANAGEMENT}

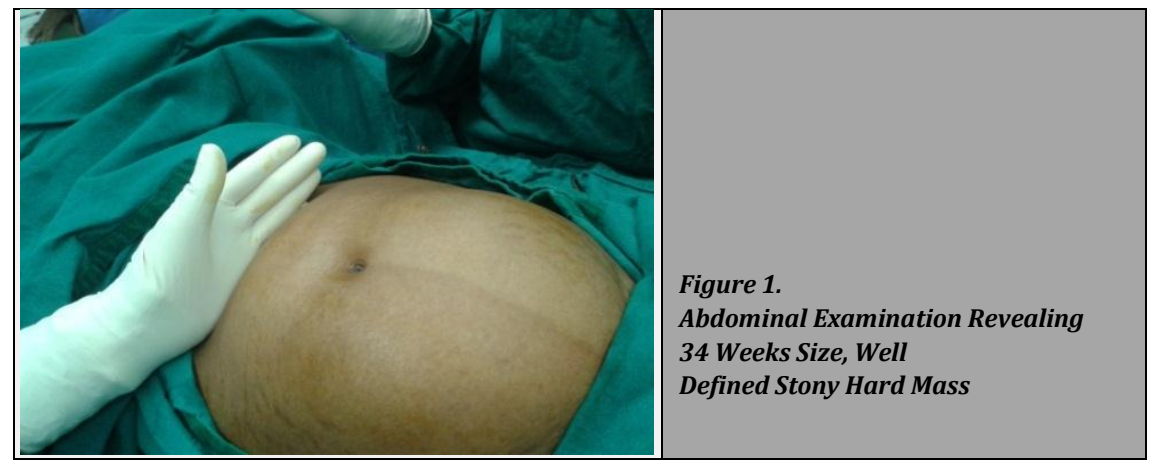

Patient underwent staging laparotomy. On opening the abdomen, a huge mass arising from the right ovary extending upward till to the under surface of the diaphragm was seen; pouch of Douglas was filled by the same tumour about $35 \times 25$ x $20 \mathrm{~cm}$. Mass was not adherent to adjacent structures. No omental thickening. Under surface of diaphragm, paracolic gutter and left ovary was normal. No palpable paraaortic lymph nodes. $50 \mathrm{ml}$ of normal saline was injected into the peritoneal cavity and sent for HPE (Histo-Pathological Examination). Omental and pelvic peritoneal bits sent for HPE. All organs were palpated and appeared normal, no deposits. Ovarian tumour ${ }^{3}$ along with uterus, both tubes, left ovary was removed into and sent for HPE.
Corresponding Author: Dr. M. J. Anishma, 258 Velachery Main Road, Sembakkam - 600073, Chennai, Tamil Nadu, India.

E-mail: anishmabright@gmail.com

DOI: $10.14260 / \mathrm{jemds} / 2020 / 784$

How to Cite This Article: Anishma MJ, Jayanthi R, Sahitya Meda. Ovarian fibrothecoma presenting as a huge pelvic mass - a case report.J Evolution Med Dent Sci 2020;9(47):3575-3577, DOI: 10.14260/jemds/2020/784

Submission 08-06-2020,

Peer Review 02-10-2020,

Acceptance 08-10-2020,

Published 23-11-2020.

Copyright (c) 2020 Anishma M.J. et al. This is an open access article distributed under Creative Commons Attribution License [Attribution 4.0 International (CC BY 4.0)] 


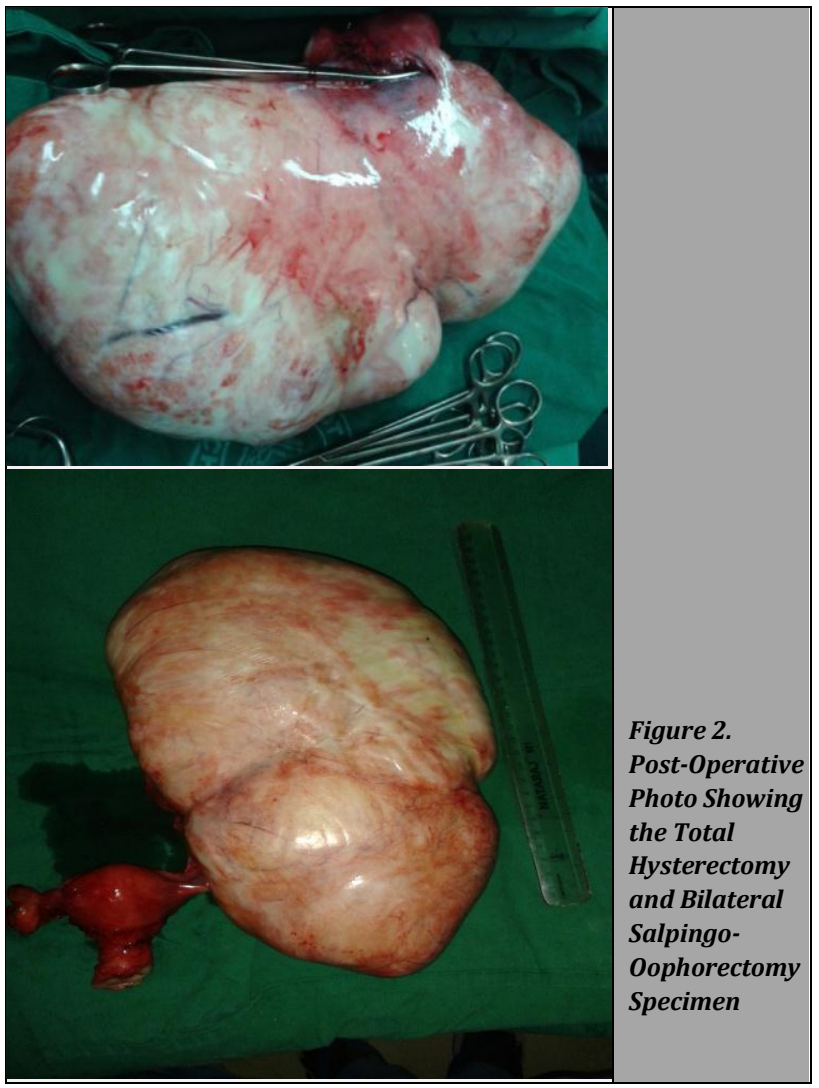

\section{PATHOLOGICAL DISCUSSION}

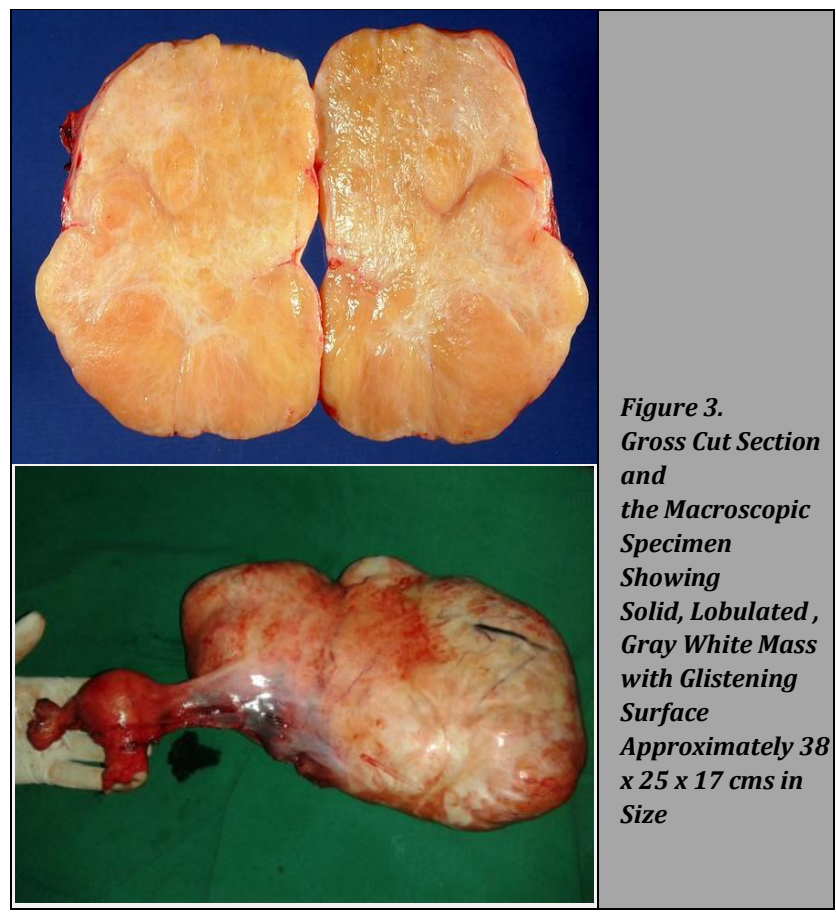

Histopathology Report

Macroscopic Examination

Solid, lobulated, greyish white mass with glistening surface $(38 \times 25 \times 17 \mathrm{~cm})$
Microscopic Examination

Collection of uniform spread of luteinized theca cells surrounded by spindle ovarian stromal cells with benign nucleus. No evidence of cystic degeneration or necrosis.

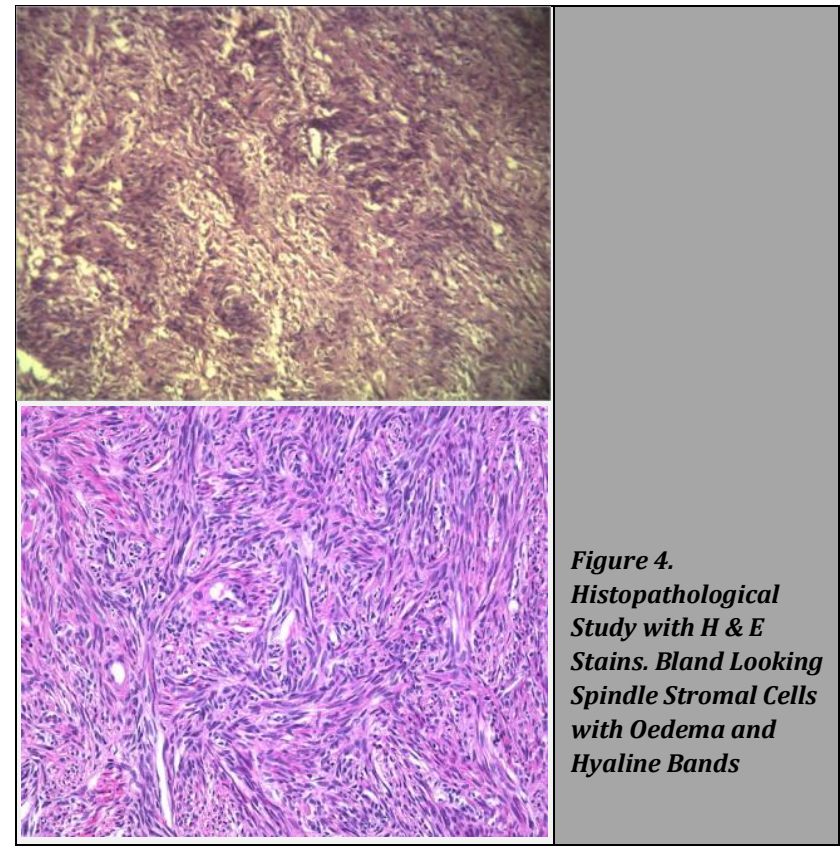

\section{DISCUSSION}

Fibrothecomas are the solid primary ovarian tumours and are frequently misdiagnosed as uterine fibroids. Incidence is $3-4$ $\%$ of all ovarian tumours, rarely malignant and in $90 \%$ of the cases are unilateral. Myxoid and cystic degeneration ${ }^{4}$ are common while calcification and haemorrhage are rare. Torsion ${ }^{5}$ is not an uncommon presentation occurring in $8 \%$ of patients. Endocrine manifestation is possible. Early diagnosis 6 and surgical resection is the treatment ${ }^{7}$ of choice.

\section{CONCLUSIONS}

Clinical presentation is often non-specific, patients present with pelvic mass, and pelvic pain. Surgical excision is the preferred treatment for perimenopausal women and is associated with good prognosis.

Financial or other competing interests: None.

Disclosure forms provided by the authors are available with the full text of this article at jemds.com.

\section{REFERENCES}

[1] Mak CW, Tzeng WS, Chen CY. Computed tomography appearance of ovarian fibrothecomas with and without torsion. Acta Radiol 2009;50(5):570-5.

[2] Angeles RM, Salem FL, Sirota RL. A right ovarian mass in a 71-year-old woman with ascites and elevated CA 125 level. Fibrothecoma of the right ovary. Arch Pathol Lab Med 2005;129(5):701-2. 
[3] Liu H, Hao SH, Li WM. Giant malignant ovarian fibrothecoma involved with retroperitoneal structures mimicking a retroperitoneal sarcoma. Arch Gynecol Obstet 2009;279(5):763-5.

[4] Takeshita T, Shima H, Oishi S, et al. Ovarian fibroma (fibrothecoma) with extensive cystic degeneration: unusual MR imaging findings in two cases. Radiat Med 2005;23(1):70-4.
[5] Bazot M, Ghossain MA, Buy JN, et al. Fibrothecomas of the ovary: CT and US findings. J Comput Assist Tomogr 1993;17(5):754-9.

[6] Imaoka I, Wada A, Kaji Y, et al. Developing an MR imaging strategy for diagnosis of ovarian masses. Radiographics 2006;26(5):1431-48.

[7] Chechia A, Attia L, Temime RB, et al. Incidence, clinical analysis, and management of ovarian fibromas and fibrothecomas. Am J Obstet Gynecol 2008;199(5):473e14. 